\title{
Effectiveness of Blended Approach in Teaching and Learning of Language Skills in Saudi Context: A Case Study
}

\author{
Jameel Ahmad ${ }^{1}$ \\ ${ }^{1}$ Applied College, King Abdulaziz University, PO box 80283, Jeddah 21589, Saudi Arabia \\ Correspondence: Jameel Ahmad, Applied College, King Abdulaziz University, PO box 80283, Jeddah 21589, \\ Saudi Arabia.
}

Received: September 14, 2021

Accepted: October 25, 2021

Online Published: October 29, 2021

doi: $10.5539 /$ elt.v14n11p118

URL: https://doi.org/10.5539/elt.v14n11p118

\begin{abstract}
The blended approach serves as an effective interface between web-based and face-to-face teaching and learning of language skills. It offers the best of both and commoditizes broad-based teaching and learning avenues thereby bringing the whole teaching and learning process to life. An empirical study conducted on EFL/ESP teachers and learners of Saudi universities indicates that adopting a fully online or a fully offline approach is not as effective as a blended approach. The overwhelming majority of the respondents illustrate that a blended approach offers a rich variety of alternatives combining both online and offline platforms. It is also evident from the findings of the current study that even a technophobic teacher of the old generation can enrich his pedagogical effectiveness while navigating and integrating a vast variety of authentic online resources in his face-to-face teaching. Nevertheless, a learner can also learn language skills effectively by interacting with the dynamic instructors in a face-to-face environment and by repeatedly using online audio-video learning resources at his convenient time. In fact, modern learners are becoming more tech-savvy owing to an exponential growth of Internet usage during the current pandemic of COVID-19, and hence willing to embrace digital learning to enhance their learning experiences. So, let both get intertwined and go hand in hand to revitalize both teaching and learning activities. The amalgamation of the interactive dynamic environment of offline and individualized/independent learning online offers a rounded learning experience.
\end{abstract}

Keywords: blended learning, effectiveness, pedagogy, authentic resources, environment

\section{Introduction}

Based on both virtual and face-to-face environments, a blended approach might be considered as an acceptable unified platform for teaching and learning language skills. Neither a fully online nor a fully offline is, ipso facto, as productive as a blended approach which increases flexibility and convenience over how and when a learner uses it. Some of the Saudi EFL learners getting enrolled in different Saudi universities with less exposure to English feel elusive while learning English fully online during the ongoing surge of COVID-19. Similarly, the faculty members also feel disappointed while teaching unenthusiastic freshmen fully online. Teachers and learners both were left with no option except a fully online provision worldwide during the ongoing pandemic of COVID-19. Out of compulsion, a fully online approach was the only offshoot to be given the go-ahead across the globe to prevent the complete closure of the entire pedagogical system.

In compliance with the compulsion, Saudi universities also took some quick and pragmatic steps to train their faculty members on how to teach well on Blackboard Collaborate Ultra. Hence, teaching was fully scheduled online, thereby, making teachers and learners firmly committed to a completely online approach. "Oh well, half a loaf is better than none". But the proficiency level the Saudi learners achieved in language skills during the current pandemic was a lot less. The quantitative and qualitative surveys conducted in this study indicate that a considerable percentage of EFL/ESP teachers and learners were found discontent with a fully online approach. Teachers' ability to identify learners' level of motivation and engagement in online classes remains sceptical. On the contrary, a teacher can easily explore who is active or not active in a face-to-face environment. However, fully face-to-face teaching and learning environments fail to cope with the aspirations of technology-mediated learners because only an offline approach hardly enhances self-paced and independent learning experiences.

The idea of doing empirical research on the blended approach occurred to me when I was assigned to teach fully on Blackboard Collaborate Ultra during the ongoing pandemic of GOVID-19 which disrupted education like 
never before. A pedagogical upheaval emerged from the first lockdown. Consequently, it was made mandatory for faculty members to access Blackboard Collaborate Ultra and upload all quizzes and teaching materials entirely on this platform. While pursuing the given schedule, I observed a crucial potential in teaching fully online along with uploading the customized teaching resources on it. The important factor is that the uploaded teaching resources on this e-learning tool enabled learners to use them repeatedly to enhance their language skills. But the inherent lacuna in fully online classes was also evident. It was almost impossible to motivate unenthusiastic learners who log in just to register their attendance. Conversely, my lifelong teaching experience in a fully face-to-face environment tells a unique story. Despite numerous benefits of offline classes, I found a complete loss for those students who missed their classes on regular basis and didn't take on responsibilities for independent learning. Hence, it is deduced that both offline and online provisions are not without their weaknesses. So, it was inevitable for me to unify the best of both online and offline approaches and explore their effectiveness. In addition, I made an extensive and intensive reading of empirical research papers on the said topic. I found just a few studies with scant data on the effectiveness of the blended approach in the Saudi context. This calls for immediate empirical research on the amalgamation of online and offline approaches in teaching and learning of language skills specifically in the Saudi context which might replicate similar implications in other non-English speaking countries. A contrastive analysis of these two approaches has hardly been touched upon before. Just a few separate studies either on face-to-face or on virtual teaching were found on Google search, but a contrastive analysis of both has never been done before specifically in the Saudi context. This prompted me to undertake a pioneering initiative to explore the effectiveness of the blended approach in teaching and learning language skills

It is interesting to note that during the COVID-19 pandemic, flipped learning model, instead of a fully offline or a fully online, needs to be adopted. A flipped model encourages blended learning shifting from teachers-centered to learners-centered where learners get more opportunities to interact in hands-on activities and learn by doing. The blended approach signifies a balanced synthesis of both offline and online approaches and transforms learning into a dynamic and interactive environment where the educator serves as a "guide on the side" rather than as a "sage on the stage". In fact, a flipped classroom model encourages learners to acquire autonomous, life-long learning skills, because they can learn independently anytime or anywhere. The online component of the blended approach offers a plethora of electronic platforms which can be integrated into a face-to-face teaching environment. For example, TOEFL Mastery, Accelerated English, Rosetta Stone, Aesop's Fables, and The Animals can be used to improve listening skills. To improve pronunciation, Sounds American, Conversations, Firsthand Access, The Lost Secret can be used. Educators and learners can also use other CALL programs such as Reading Adventure 1-ESL, MacReader, Reading Critically, Steps to Comprehension, and games (HangWord). Some software has also been designed to support writing skills, such as Sentence Combining, Sentence Maker, and Typing Tutor.

The fact is that offline and online approaches need to be intertwined to make teaching and learning more effective. The balanced integration can enhance learners' pronunciation, extensive vocabulary, communicative grammar, and integrated language skills. The ESL/EFL/ESP teachers can integrate technology into a face-to-face environment and revolutionize the whole language learning process. If technology is fully integrated into the f2F environment, the learner is most likely to improve his linguistic competence. The online language games fascinate EFL/ESL learners for learning linguistic knowledge and skills with excitement. Digital Play, from Delta Publishing, is also a significant App in terms of learning language skills. The EFL learners can download the free app to enhance their proficiency in English. A significant interactive tool, WORDREADY, is used to improve word power related to day-to-day communication.

\subsection{Literature Review}

Amid numerous references pertaining to the blended approach, only a few references that are more relevant are included in the literature review. The blended approach is equally beneficial for both teachers and learners. On the one hand, a teacher besides his face -to face teaching, maximizes his teaching abilities while uploading his customized teaching materials on e-learning tools. Similarly, a learner too gets opportunities to personalize his learning behavior in addition to the face-to-face provision. Keeping this view, So and Bonk (2010) considered the application of the blended approach in teaching and learning more daunting because it turns students somewhat proactive and autonomous. Kern, R. and Warschauer, M. (2000) observed that broadband-related technologies are extremely productive because learners can get a better chance to interact with native speakers online and develop their intellectual, professional and language skills. According to Battro, AM (2004), "ELT practitioners can provide scaffolding in the overall language-learning objective through technological devices". According to Beckett and Miller (2006), technology mediated approach continues to have cumulative effect on 
language learning activities, such as oral practice and reading and writing skills development. Jackson et al. (2006) conducted an empirical survey in which they found that students relying on Internet-based learning, in addition to face-to-face environment, got higher scores and grades. Baturay et al. (2010) also endorsed the idea that technology-based instructions offer enriched incorporated multimedia grammar contents. Whyte (2011) endorsed the implementation of the blended approach because it has immense potential to increase learning outcomes. Ituma (2011) was of the view that the limitation of exclusive virtual or face-to-face teaching and learning can be addressed only by adopting a more blended approach to teaching and learning language skills.

Based on an empirical study, Shibley, Amaral, Shank, and Shibley (2011) found a blended approach more effective than fully face-to-face teaching. To them, a synthesis of both can enhance teaching and learning of language skills. According to Johnson (2014), the blended approach increases learners' active involvement and engagement in the whole process of learning language skills. According to Marsh (2012:16), blended learning can create confident learners by getting learners exposed to authentic learning materials.

Motteram, Onat-Stelma and Slaouti (2012) found massive use of technologies more productive in learning language skills. They also explored that computer- mediated approach is more useful to teach integrated language skills. Hassan Ja'ashann (2015) conducted a survey on students who found blended learning more productive than either a fully online or a fully offline teaching/ learning of language skills. According to Dudeney \& Hockly (2016) today's learners are exposed to technology since childhood, so, online learning will be equally effective. It is proven that the synthesis of both can make learning more efficient in both face-to-face and virtual environments. C. Banditvilai (2016) conducted an empirical study on ESP students about blended learning. He aligned online teaching with classroom instructions and found that the students had remarkably enhanced their language skills. Walsh (2016) was a strong supporter of the blended approach owing to its limitless potential to maximize language teaching and language acquisition. Akbarov, Gönen, and Aydoğan (2018) examined the learners' perceptions about blended learning and found EFL students' massive preference of balanced synthesis over the traditional approach. They found the blended approach as an effective learning model because it enriches teaching and learning environments in an EFL context. Zhang and Zhu (2018) conducted a study on 5376 ESL students at a Major University in Beijing and found that the students who adopted the blended approach performed far better.

\subsection{Hypothesis}

It is hypothesized that a blended approach will be the best panacea for teaching and learning language skills. The blended approach is a unified synthesis of face-to-face and virtual approaches that assist each other and work effectively. The present hypothesis consists of the following statements:

1) If the blended approach is implemented, it will give double platforms for teaching and learning language skills.

2) Back-and-forth discussion and group learning activities are more robust in a face-to-face environment rather than in a virtual environment.

3) If a fully online approach is implemented, it might be difficult for an instructor to monitor unenthusiastic learners.

4) Compared to a full face-to-face, a virtual approach facilitates learners beyond boundaries.

5) In face-to-face teaching, an instructor can easily find out who is an active and a non-active student and can appy remedial measures accordingly.

\section{Methods}

The present empirical research embarks on primary data as well as secondary data. Both constitute the methodology of this research and help the researcher explore what the EFL educators and students have practically observed about the effectiveness of the blended approach in teaching and learning language skills.

\subsection{Primary Data}

Based on the quantitative survey, the primary data include statements about the effectiveness of blended approach compared to a fully online or a fully offline approach in teaching and learning language skills. The experience-based responses were elicited from male faculty members and male students of Saudi universities. It was not easy for me as a male faculty member to draw the responses from female counterparts owing to traditional hindrance. Therefore, the present study relies merely on male participants. A couple of structured statements were administered with a view to drawing primary data from randomly selected teachers and students of Saudi universities. 


\subsection{Secondary Data}

The secondary data were drawn from online resources such as ELT books and research papers that are related to the said topic. The intensive and extensive reading outputs on the said topic were collected from the following authentic published sources:

1) Online resources include research papers on effectiveness of the blended approach.

2) Articles on the effectiveness of blended approach published by BBC world service.

3) Strategic plans of Saudi universities about the implementation of blended approach in teaching and learning of language skills.

4) Different magazines and daily newspapers regarding EFL learning in Saudi Arabia.

\subsection{Data Collection Methods}

Data collection methods were carried on the basis of the quantitative and qualitative surveys. These two surveys were conducted on both teachers and learners to collect the primary data. A quantitative method was used to obtain the valuable feedback of Saudi EFL and ESP teachers and students in large numbers on the said topic which determines their statistically analyzable probability value. The statistical procedures were applied to give the definitive or nearly definitive result on the basis of responses to different statements.

The quantitative survey is emphatically an important means of data collection. According to Cohen, Manion, \& Morrison (2007), the quantitative survey aims to explore the massive response from the participants. However, innumerable empirical data indicate that just relying on self-reporting statements usually depicts an incomplete picture of the situation. Therefore, Pintrich and Schunk (2002) besides quantitative survey, also realized "the nitty-gritty of qualitative survey in order to delve deeper by having group discussion and individual interviews". The present research contains the frequently used Likert five-point scales which are usually conducted in empirical research to measure how much or what degree the participants agree or disagree with a particular statement.

\subsection{Data Analysis}

Data analysis was carried out both quantitatively and qualitatively. Figures and tables were used to validate exact statistical findings. Percentages were utilized to show the participants' overwhelming response on the effectiveness of the blended approach in teaching and learning of language skills. One thousand respondents including the EFL/ESP specialists and students of Saudi universities participated in the present research and revealed their experiences forthrightly. The respondents were asked to check strongly agree/agree/do not know/disagree/strongly disagree on the statements pertaining to the effectiveness of the blended approach. The sample of statements related to the effectiveness of the blended approach is given below Sample 1. Statements on the effectiveness of the blended approach in the teaching of language skills:

1) Compared to a fully offline, or a fully online, a blended approach is more effective in teaching language skills.

2) It is difficult for an instructor to motivate unenthusiastic learners in a fully online class.

3) The blended approach allows instructors to make the best of both online and offline approaches.

4) An instructor can facilitate learners beyond boundaries while adopting a blended approach.

5) An instructor can monitor well a back-and-forth discussion and group learning activities in $\mathrm{f} 2 \mathrm{f}$ environment.

6) Sample ii. Statements on the effectiveness of the blended approach in learning language skills.

7) A blend of $70 \%$ offline and $30 \%$ online will be more effective during the current outbreak of COVID-19.

8) A blended approach facilitates both regular and working-class learners to learn offline as well as online.

9) Learners can improve their reading and writing skills more in a face-to-face nvironment rather than in a virtual class.

10) Back and forth discussion, group learning activities, are more robust in a face-to-face environment rather than in an online class.

11) A blended approach gives learners double platforms to enhance their language skills. 


\section{Results and Discussion}

The findings of Figure 1 based on the quantitative and qualitative surveys conducted on ELT educators of Saudi universities are worth noting. This survey was conducted during COVID-19 pandemic where all teaching faculties were given no option except to adopt a fully online approach in teaching language skills. They experienced that fully online teaching on any e-learning platform cannot produce the desired result, because unenthusiastic learners easily betray even a firmly committed instructor. The unmotivated learners remain impervious to a fully prepared online teaching. Similarly, in a face-to-face environment, if a regular student missed the class somehow, he is left with no alternative. Therefore, face-to-face teaching and learning can be made more effective if they are integrated with technology-mediated teaching and learning.

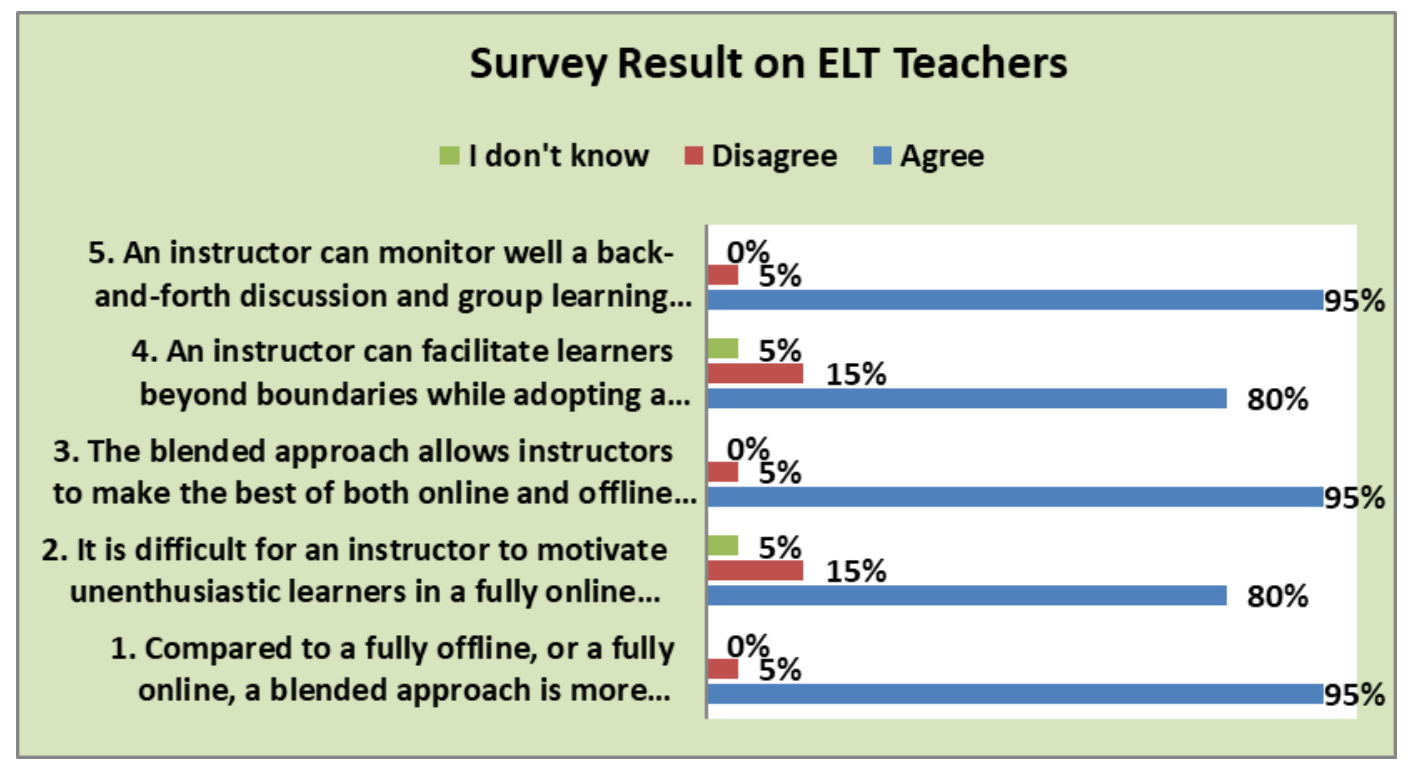

Figure 1. Results of the survey conducted on teachers about blended approach

This survey is rooted in the world of English Language Teaching (ELT). The ELT instructors from different nationalities working in Saudi universities participated in the quantitative and qualitative surveys of this empirical study. Their responses to the first statement are based on their real experiences while adopting a fully online approach in teaching language skills during the current COVID-19 pandemic scenario. The statistical findings indicate how well the participants liked the blended approach. $95 \%$ of respondents agreed that compared to fully online or fully offline teaching, a blended approach is more effective in teaching language skills. Almost all the ELT practitioners validated this statement of the quantitative survey. Only $5 \%$ of respondents were found at variance with the said statement. So far as the qualitative survey is concerned, it seems to be more cogent because it explores the nitty-gritty of the responses of the quantitative survey. In fact, the qualitative survey encapsulates a wide spectrum of the finding based on the real experience and the valid argument emerged from the real context. While interviewing I found most ELT teachers arguing that both offline and online approaches have their own profound impact on teaching, but both are not without their flaws. Therefore, it is essential to unify the best of both by using technology-mediated elements alongside traditional face-to-face teaching. Instructors can use online resources for extension activities to complement their face-to-face sessions.

Teachers have been using face-to-face teaching since time immemorial, whereas a fully online teaching has emerged as an inevitable offshoot for regular students during the recent outbreak of coronavirus. It has enriched pedagogical methods leaving teachers with no option except to become a computer literate to create their own web-based teaching materials and upload their customized teaching contents on e-learning platforms.

The findings of the qualitative survey also reflect the effectiveness of the blended approach in various domains of language skills. One of the notable ELT teachers argued: "a fully online approach will be ineffective in teaching writing skills". He frankly shared his real experience explaining that whenever any writing task was given, $80 \%$ of the learners copied from Google and pasted. Therefore, let the writing task be better monitored in a traditional face-to-face environment. So, whatever lacks in online teaching could be compensated well in face-to-face teaching and vice versa. Another British teacher of English supported the blended approach and said "Even if a few students missed face-to-face teaching but they can get avail of uploaded online teaching videos 
and reinforce their listening and speaking skills", Another American ELT specialist also supported the integration of offline with the online approach. To him making the best use of online authentic resources, students are most likely to improve their pronunciation and accentual patterns of the English language. Hence, ELT teachers can't ignore the immense benefits and effectiveness of online provision. They must adopt a complete unification of offline and online in the ELT context. It can be deduced from both the surveys that the blended approach needs to be a major part of the landscape of pedagogical richness and effectiveness. The adoption of face-to-face teaching has undoubtedly laid a tremendous impact on both enthusiastic and unenthusiastic learners, whereas a fully online approach abysmally fails to inspire unenthusiastic learners. The feedback of ELT teachers in this regard might replicate the global perspective.

In response to the second statement, a growing consensus was observed among ELT educators in favor of the statement. $80 \%$ of them agreed that it was almost impossible to monitor unenthusiastic learners. Only $15 \%$ of the respondents were found to disagree with the said statement. I also stand with $80 \%$ of respondents keeping in view the callous attitude of unenthusiastic learners towards fully online teaching. The $80 \%$ responses were further corroborated in the qualitative survey where ELT teachers came up with their valid arguments in favor of the statement.The qualitative survey in this regard suggests that only fully online teaching can hardly address the indifferent attitude of unmotivated learners. Therefore, one of the respondents said, "All the students are simultaneously under surveillance in a face-to-face teaching which is not possible in an online class". I entirely agree with him because I have had similar observations while taking fully online classes for the past one -and -a half - years. Another Asian ELT teacher said, "An unenthusiastic learner can log in but can stay unattentive without being noticed in an online class". While elaborating he argues that the unmotivated learners $\log$ in just to register their attendance rather than to get avail of the online lecture. On the contrary, a teacher can easily find out who is active and who is not active in face-to-face teaching. He can then apply remedial measures to improve the learning behavior of unmotivated learners. Therefore, most of the respondents were of the view that a fully online teaching alone without integrating a face-to-face environment will be inadequate especially for freshmen who lacked e-Learning experience in their previous English classes.

The statistical result of the third statement is the hallmark of this empirical study. 95\% of ELT educators consented that the blended approach allows the best use of both virtual and face-to-face approaches. Only $5 \%$ of them were found to disagree with the statement. Almost all of them arrived at a concurrence that the unification of face to face and e-learning strategies will doubly enhance teaching and learning opportunities. There is no doubt that both offline and online strategies have their strengths and weakness, so, a balanced integration based on the context will be more productive. A blended approach enables an innovative instructor to teach offline and to upload his customized teaching materials on an e-learning platform so that the learners can practice them repeatedly at their convenient time. The respondents of the quantitative survey realized the impact of authentic online resources on pedagogical effectiveness. It also emerged from the qualitative survey that online teaching will be a source of immense inspiration for web-based learners. A synthesis of both offline and online teaching will enhance learners' aptitude for learning and correspond well with their aspirations. Some faculty members also argued that the course books prescribed for English language teaching are sometimes above the proficiency levels of Saudi learners. An instructor can make his teaching more relevant and effective by uploading his customized teaching materials on e-learning platforms.

In view of the fourth statement, $80 \%$ of respondents firmly believed that an instructor could facilitate learners beyond boundaries owing to the potential the technology-mediated teaching contains in itself. Only $15 \%$ of respondents manifested their disagreement and 5\% remained neutral. By integrating online teaching into a face-to-face environment, an instructor can surpass all limitations of face-to-face teaching. In a face-to-face environment, an instructor can facilitate only active students rather than absentees whereas he can equally facilitate absentees by uploading his teaching materials on e-portals. This way, the students who are absent from the class due to some reasons can make the best use of uploaded teaching materials at their convenient time. A considerable number of participants in the group -interviews consolidated their arguments by saying that any pedagogy without integrating e-learning tools with chalk-face experience can't give the optimal results. One of the American teachers said, "an instructor can reach those who are unreachable by uploading his customized teaching resources on e-learning platforms". Another teacher said "Configuration of technology in $\mathrm{f} 2 \mathrm{f}$ teaching is really encompassing because it supports flexible opportunities and benefits learners even if they somehow missed the class".

The statistical findings of the fifth statement indicate that $95 \%$ of ELT instructors agreed that they could monitor well and actively engage learners in back-and-forth discussion and group learning activities. Only $5 \%$ of respondents opposed the statement. With a view to improving learners' communication skills, a face -to face 
teaching is more effective than virtual teaching. In a face-to-face environment, an instructor can announce the topic and open the floor for discussion. He can motivate even unenthusiastic learners to break their silence and tend to interact with their friends in the class about the given topic. Standing in front of learners, an instructor can instill in them enthusiasm for speaking skills. Learners' frenzy to rebut can obliterate their hesitation and ignite their readiness to speak in a face-to-face environment.

The arguments of the qualitative survey are substantially convincing. One of the participants opined that "back and forth discussion or group learning activities can be monitored more effectively in a face-to-face teaching rather than in an online teaching". Another ELT teacher of Asian nationality, who was laden with real experience while teaching fully online, came up with a convincing argument. According to him, "only motivated learners were found committed in their group learning activities in fully online classes. In fact, it was very difficult for him to engage unenthusiastic learners in group discussion". In face-to-face teaching, a teacher can monitor learners' progress and give immediate feedback laying a huge impact on learners to improve their communication skills.

\section{Survey Result on Learners}

$$
\text { I don't know } \quad \text { Disagree } \quad \text { Agree }
$$

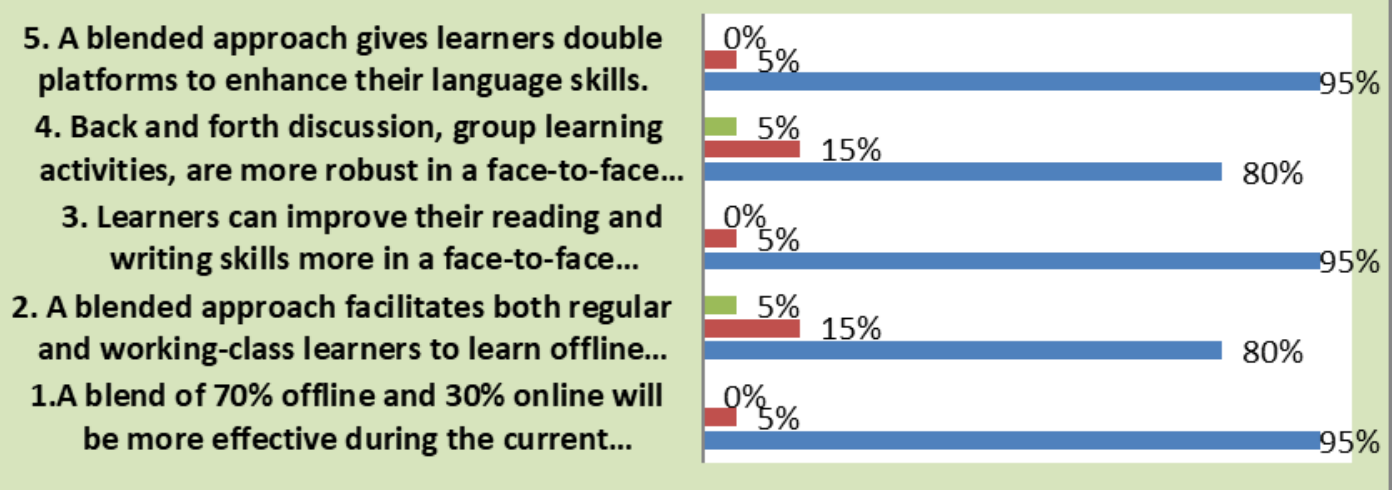

Figure 2. Results of quantitative survey conducted on learners

The second survey was conducted on the Saudi students of intensive English and ESP courses prescribed in different Saudi universities. The statistical result of the quantitative survey is an eye-opener. It emerged from the survey that the ratio of the blend is totally contextual. It differs from country to country and situation to situation. Neither offline nor online learning is better than the blended approach in learning language skills. In a digital age where learners are becoming more technoids, online learning needs to be integrated with offline learning. However, determining the ratio of blend depends on the requirement of learners. In this quantitative survey, $95 \%$ of Saudi learners approved the blend of $70 \%$ offline and $30 \%$ online. As a matter of fact, digital learning has revolutionized learners' aptitude. The inclusion of gaming has an added advantage in contributing fun to the whole learning process. The qualitative survey on the first statement illustrates Saudi learners' acceptance of the given ratio of blend. In group interviews, the overwhelming majority came up with this cogent argument "As the situation is getting back to normalcy, a blend of $70 \%$ offline and $30 \%$ online will be more effective than a fully online or a fully offline". Another respondent justified his viewpoint by saying: "This ratio of the blend will be more productive especially for freshmen who got enrolled in any Saudi universities with inadequate linguistic background". In nutshell, it can be deduced that almost all Saudi learners hailed the implementation of $70 \%$ offline and $30 \%$ online learning provisions.

This is undeniable that blended learning equips learners with diverse campus experience and flexibility of independent learning experiences. In response to the second statement, $80 \%$ of respondents accepted that the blended approach serves both regular and working-class/adult learners. Only $15 \%$ of learners opposed the statement and 5\% remain neutral. A face-to-face environment can serve regular students whereas uploaded teaching materials on e-learning tools can facilitate both regular and working-class learners. The consistent growth in Internet usage enables working-class learners to embark on the customized learning resources uploaded on the e-learning platform. Independent learners can navigate hundreds of learning resources and use them to improve all integrated language skills. The arguments of the qualitative survey consolidate the statistical responses of the quantitative survey. One of the working-class learners opined that working-class or adult 
learners couldn't be left behind in the digital age, because authentic learning resources are available online in abundance. They can easily navigate on Google and find a variety of relevant online resources that motivate learners to use them anytime and anywhere to improve their language skills. The emergence of new technology and e-learning tools has inculcated a renewed interest in learners to enhance their language skills.

In response to the third statement, the learners categorically revealed what they have experienced during their fully online classes. They got a better chance to analyze both online and offline learning contrastively. Hence, $95 \%$ of learners unanimously agreed that they learned reading and writing skills more effectively in a face-to-face environment rather than in a virtual class. Only $5 \%$ of respondents were found to disagree. In a qualitative survey, they explained why they preferred offline learning to online learning to enhance reading and writing skills. The arguments of the respondents in the group interviews indicate that those learners are monitored well to improve their reading and writing skills. A teacher can distribute reading activities among different students to convert reading comprehension into a group learning activity. One of the learners may be asked to read properly, whereas the second one to explain, the third one to correct the pronunciation and the fourth one might be asked to explain the difficult words that occurred in the paragraph. This is the manifestation of learners-centered learning activities which can be monitored well in a face-to-face environment. Even the weak learners will be able to improve their reading skills which include comprehension of contents, vocabulary, pronunciation, and enhancement of communication skills. The students also opined that they could substantially improve their writing skills in a face-to-face environment. Teachers can move around and guide the students on how to make correct sentences with grammar accuracy. Learners can brainstorm to share new ideas about the topic. In face-to-face teaching, an instructor can monitor well peer-to-peer or group writing activities. The students can interact with each other and share each other's scripts to improve ideas and language accuracy.

In response to the fourth statement of the quantitative survey, $80 \%$ of learners strongly believed that learners could enrich back-and-forth discussion and communication skills more in a face-to-face context rather than in a virtual approach. Only $15 \%$ of respondents were found to disagree. Students get a better chance to interact in the class with each other and give PowerPoint presentations to improve their communication skills. The students in a group interview strengthened their responses by giving convincing arguments. One of them said, "He is most likely to improve his communication skills by interacting with his classmates in a group discussion". Another student said, "The chances for communication skills enhance if each student is assigned to give an oral presentation". As a matter of fact, the students can actively engage themselves in a back-and-forth discussion and PowerPoint presentation in a face-to-face environment, owing to their being monitored well by their committed educators.

The quantitative response of the fifth statement is worth mentioning. $95 \%$ of the respondents entirely agreed that the blended approach gives learners double flatforms to improve their language skills. The respondents confirmed that they can tremendously improve language skills by adopting a blended approach. Interactive learning in a face-to-face environment is extensively facilitated by customized teaching materials uploaded on e-learning platforms. The overwhelming response of this quantitative survey was substantiated with convincing arguments in the qualitative survey. Almost all of them believed that learners could independently use customized teaching materials repeatedly besides dynamic face-to-face learning. While listening to online audio/video scripts, learners can improve the pronunciation of difficult words by pause and rewind process. They can feel motivated to speak while listening to authentic resources repeatedly.

\section{Conclusions}

The findings of quantitative and qualitative surveys conducted on both ELT instructors and English language learners corroborate the conclusion that the implementation of blended approach is essential in digital age to cope with the current volatile situation. Blended approach offers teaching and learning opportunities both inside and outside the clasroom. By embedding technology, teachers, and learners both can have more autonomy, individualized and personalized experiences. The overwhelming response of both ELT specialists and ELT students are in favor of implementation of blended approach in teaching and learning language skills. The balanced unification of offline and online approaches has immense potential to enhance the effectiveness of teaching and learning language skills. The blended approach expands the horizon of teaching and learning of language skills, because it provides teachers and students with two effective platforms to substantiate their roles as teachers or as learners. The findings also signify that the ratio of the blend is highly contextualized and specific to each institution. The flexibility of any time / anywhere of an online approach is an added advantage and it enriches the effectiveness of both teaching and learning activities. The findings of this empirical study also indicate that tech-savvy learners in today's digital age expect the integration of technology-mediated learning with traditional dynamic campus learning for better learning outcomes. 


\section{Limitations}

The present study has certain limitations about the statistical surveys. The surveys of this study were conducted only on Saudi male ELT professionals and students. It is possible that the experience of female faculty members and students with a blended approach would have been partially or entirely different. Based on this research, other researchers can elicit the views and genuine arguments of female respondents to obtain a more pragmatic recommendation.

\section{Acknowledgments}

This project was funded by the Deanship of Scientific Research (DSR), King Abdulaziz University, KSA, under grant no. G: 335/156/1441. The author, therefore, acknowledges with thanks DSR technical and financial support. The author is indebted to all ELT educators and students of Saudi universities for participating in the quantitative and qualitative surveys conducted in this study.

\section{References}

Azamat Akbarov, A., Gönen, K., \& Aydoğan, H. (2018). Students' Attitude towards Blended Learning in EFL Context. Acta Didactica Napocensia, 11(1). https://doi.org/10.24193/adn.11.1.5

Battro, A. M. (2004). Digital skills, globalization and education. In Surez-Orozco, M. \& QinHilliard, D. (Eds.), Globalization: Culture and Education in the New Millenium. University of California Press.

Baturay, M. H., Daloglu, A., \& Yildirim, S. (2010). Language Practice with Multimedia Supported Web-Based Grammar Revision Material. ReCALL, 22(3), 313-331. https://doi.org/10.1017/S0958344010000182

Beckett, G. H., \& Miller, P. C. (2006). Project Based Second and Foreign Language Learning: Past, Present and Future. USA: Information Age Publishing.

Banditvilai, C. (2016). Enhancing Students' Language Skills through Blended Learning. Electronic Journal of e-Learning, 14(3), 220-229.

Cohen, L., Manion, L., \& Morrison, K. (2007). Research methods in education. London: Routledge. https://doi.org/10.4324/9780203029053

Dudeney, G., \& Hockly, N. (2016). Blended Learning in a Mobile Context: New Tools, New Learning Experiences? In McCarthy, M. (Ed.), The Cambridge Guide to Blended Learning for Language Teaching (pp. 219-233). Cambridge: Cambridge University Press. https://doi.org/10.1017/9781009024754.019

Hassan Ja'ashan. (2015). Perceptions and Attitudes towards Blended Learning for English Courses: A Case Study of Students at University of Bisha. English Language Teaching, 8(9). https://doi.org/10.5539/elt.v8n9p40

Ituma, A. N. (2011). An evaluation of students' perceptions and engagement with e- Learning components in a campus based university. Active learning in Higher Education Journal, 12(1), 57-68. https://doi.org/10.1177/1469787410387722

Jackson, L. A., Eye, A. V., Biocca, F. A., Barbatsis, G., Zhao, Y., \& Fitzgerald, H. E. (2006). Does home internet use influence the academic performance of low-income children? British Journal of Development Psychology, 42(3), 1-7. https://doi.org/10.1037/0012-1649.42.3.429

Johnson, C. P. (2014). Increasing students' academic involvement: Chilean teacher engagement with learners in blended English as a foreign language course (Doctoral dissertation).

Kern, R., \& Warschauer, M. (2000). Network-based language teaching: concepts and practice. Cambridge: Cambridge University Press. https://doi.org/10.1017/CBO9781139524735

Baturay, M., Daloglu, A., \& Yildirim, S. (2010). Language Practice with Multimedia Supported Web-Based Grammar Revision Material. ReCALL, 22(3), 313-331. https://doi.org/10.1017/S0958344010000182

Marsh, D. (2012). Blended Learning: Creating Learning Opportunities for Language Learners. Cambridge: Cambridge University Press.

Motteram, G., Slaouti, D., \& Onat-Stelma, Z. (2013). Second language teacher education for CALL: An alignment of theory and practice. In Thomas, M., Reinders, H. \& Warschauer, M. (Eds.), Contemporary Computer-Assisted Language Learning. UK: Bloomsbury Academic.

Pintrich, P. R., \& Schunk, D. H. (2002). Motivation in Education: Theory, Research and Applications. 
Shibley, I., Amaral, K. E., Shank, J. D., \& Shibley, L. R. (2011). Designing a blended course: Using ADDIE to guide instructional design. Journal of College Science Teaching, 40(6), 80-85.

So, H.-J., \& Bonk, C. J. (2010). Examining the roles of blended learning approaches in computer-supported collaborative learning (CSCL) environments: A Delphi study. Educational Technology \& Society, 13(3), 189-200. https://doi.org/10.12691/education-6-3-5

Walsh, S. (2016). The Role of Interaction in a Blended Learning Context. In McCarthy, M. (Ed.), The Cambridge Guide to Blended Learning for Language Teaching (pp. 36-52). Cambridge: Cambridge University Press. https://doi.org/10.1017/9781009024754.005

Whyte, S. (2011). Learning theory and technology in university foreign language education: The case of French universities. Arts and Humanities in Higher Education. https://doi.org/10.1177/1474022210364783

Zhang, \& Zhu. (2018). Comparing Learning Outcomes of Blended Learning and Traditional Face-to Face Learning of University Students in ESL Courses. International Journal on E-Learning, 17(2), 251-273. Retrieved from https://www.researchgate.net

\section{Copyrights}

Copyright for this article is retained by the author(s), with first publication rights granted to the journal.

This is an open-access article distributed under the terms and conditions of the Creative Commons Attribution license (http://creativecommons.org/licenses/by/4.0/). 